\title{
Implementasi Metode Rondo Untuk Meningkatkan Teknik Passing Mahasiswa Pada Mata Kuliah Futsal Penjas Prodi Penjas FKIP Unib
}

\author{
Sugiyanto \\ Penjas fkip unib, e-mail: sugiyantopenjas55@gmail.com \\ Universitas Bengkulu \\ Bogy Restu Ilahi \\ Universitas Bengkulu \\ Defliyanto \\ Universitas Bengkulu
}

\begin{abstract}
This study aims to find out how the Implementation of the Rondo Method to Improve Student Passing Techniques in Futsal Courses so as to improve the learning quality of seventh semester students in Class A Penjas Study Program FKIP Unib. Through the rondo method students are included in groups to practice passing. The hope is that students have an active and contributive attitude so that getting meaningful learning both individually and in groups and improving the quality of learning in Futsal courses is achieved. The subjects of this study were seventh semester students of class A Penjas Study Program FKIP UNIB who were taking the Futsal Orpil course. Data collection techniques were carried out by means of tests conducted at the beginning and at the end of the cycle, there was an increase in the skills of basic passing techniques before and after using the rondo method in the first cycle, which proved to be an increase of $50 \%$ of 20 students who received complete grades from 40 students based on details percentage value (A) 12 people, (B) 8 people, (C) 20 people using the rondo method with 1 person being a guard. In cycle II there was an increase in passing skills in the rondo futsal game method with 2 students who became guards. Evident from the results of the study with the results of a $65 \%$ increase in completeness from the first cycle which only $50 \%$ completed from 40 students with details of the value (A) 16 people, (B) 9 people, (C) 15 people. There was an increase from the first cycle, namely $15 \%$ increase with completeness from 20 students to 26 students who completed Futsal learning
\end{abstract}

\section{Keywords: Rondo, Passing, Futsal}

\section{PENDAHULUAN}

Salah satu matakuliah wajib mahasiswa S1 Prodi Penjas FKIP Unib adalah matakuliah Futsal yang memiliki bobot 2 SKS. Mata kuliah Olaharaga Pilihan (Orpil) ini diberikan pada semester ganjil (VII) dengan capaian pembelajaran yaitu mahasiwa mampu memahami serta melaksanakan permainan olahraga futsal dengan baik. Olahraga futsal itu sendiri terdapat teknik-teknik dasar yang harus dikembangkan sehingga tercipta permainan yang berkualitas. Adapun teknik dalam bermain futsal yaitu: teknik mengontrol bola, teknik mengumpan bola, teknik menggiring bola, teknik menendang bola, kecepatan dan fisik. Salah satu teknik dasar yang diajarkan dalam mata kuliah Futsal adalah teknik 
mengumpan bola (passsing). Teknik ini harus dikuasai oleh mahasiswa dengan memanfaatkan momentum mengoper atau memindahkan bola dari satu pemain ke pemain lainnya. Observasi awal yang dilakukan memperlihatkan adanya kecenderungan yang terjadi pada permainan futsal yang dilakukan oleh mahasiswa Penjas FKIP Unib. Permasalahan tersebut adalah mahasiswa sering kehilangan bola dan salah mengoper bola. Selain itu, mahasiswa cenderung menekankan pada kegiatan mencetak gol daripada pelaksanaan permainan yang berkualitas melalui implementasi teknik-teknik bermain futsal. Oleh karena itu dibutuhkan suatu strategi pembelajaran untuk meningkatkan kualitas pembelajaran dalam matakuliah futsal.

Rondo atau dikenal juga dengan istilah kucing-kucingan adalah sebuah metode untuk meningkatkan kemampuan passing yang diimplementasikan pada seluruh level pemain sepak bola. Metode ini mengharuskan beberapa orang (minimal tiga orang) untuk saling mengoper bola. Menurut Johan Cruyff dalam buku Our Competition is the World, rondo atau kucing-kucingan memasukkan hampir semua aspek dalam permainan sepak bola kecuali shooting. Aspek kompetitif, membuka ruang, apa yang harus dilakukan saat ball possesion, saat sedang memegang bola, menjaga ketat lawan dan merebut bola. Tentu saja hal ini akan membantu mengasah teknik bermain bola (dalam penelitian ini adalah futsal) yang ada pada diri mahasiswa. Melalui metode Rondo yang diterapkan pada matakuliah futsal, peneliti berharap terjadi peningkatan teknik dasar passing dengan kaki bagian dalam, passing dengan kaki bagian luar, dan passing dengan punggung kaki pada mahasiswa saat pembelajaran praktek matakuliah futsal sehingga kemampuan passing mahasiswa meningkat dan hasil yang dinginkan dalam pembelajaran pun tercapai.

\section{METODE PENELITIAN}

Penelitian ini merupakan Penelitian Tindakan Kelas (Classroom Action Research), yaitu suatu penelitian tindakan dalam lingkup pendidikan yang dilakukan dosen, dan sekaligus sebagai peneliti dikelasnya atau bersama-sama dengan orang lain (kolaborasi) dengan jalan merancang, melaksanakan, dan merefleksikan tindakan secara kolaboratif dan partisipasif yang bertujuan untuk memperbaiki atau meningkatkan mutu (kualitas) proses pembelajaran dikelasnya melalui suatu tindakan (treatment) tertentu dalam suatu siklus (Kunandar, 2011).

Penelitian ini mengunakan metode deskriptif dikarenakan dalam penelitian ini akan dihasilkan sebuah deskripsi tentang sejauh mana peningkatan kualitas pembelajaran dengan menggunakan Metode Rondo pada mahasiswa yang menjadi sampel penelitian. Penerapan metode pembelajaran tersebut dalam matakuliah futsal memungkinkan mahasiswa Memiliki kemampuan passing yang meningkat sehingga pembelajaran Futsal mendapatkan hasil yang dinginkan dalam pembelajaran pun tercapai. 


\section{HASIL DAN PEMBAHASAN}

A. Hasil Penelitian

Perolehan Nilai Mahasiswa Siklus I dan II

\begin{tabular}{|c|c|c|c|c|c|c|c|}
\hline $\begin{array}{c}\text { Rent } \\
\text { ang } \\
\text { Nilai }\end{array}$ & $\begin{array}{l}\text { H } \\
\text { ur } \\
\text { uf }\end{array}$ & $\begin{array}{c}\text { Deskr } \\
\text { ipsi }\end{array}$ & \multicolumn{2}{|c|}{$\begin{array}{c}\text { Peroleha } \\
\text { n Nilai } \\
\text { Siklus I }\end{array}$} & \multicolumn{2}{|c|}{$\begin{array}{c}\text { Perolehan } \\
\text { Nilai } \\
\text { Siklus II }\end{array}$} & \multirow{2}{*}{$\begin{array}{c}\text { Tar } \\
\text { get } \\
\text { Cap } \\
\text { aia } \\
\mathbf{n} \\
0 \%\end{array}$} \\
\hline $\begin{array}{l}90- \\
100\end{array}$ & $\begin{array}{l}\text { A } \\
+\end{array}$ & $\begin{array}{l}\text { Istim } \\
\text { ewa }\end{array}$ & 0 & $0 \%$ & 0 & $0 \%$ & \\
\hline $\begin{array}{c}80- \\
89\end{array}$ & $A$ & $\begin{array}{c}\text { Baik } \\
\text { Sekali }\end{array}$ & $\begin{array}{l}1 \\
2\end{array}$ & $30 \%$ & 16 & $40 \%$ & $35 \%$ \\
\hline $\begin{array}{l}70- \\
79 \\
\end{array}$ & $B$ & Baik & 8 & $20 \%$ & 9 & $\begin{array}{c}22,5 \\
\%\end{array}$ & $21 \%$ \\
\hline $0-69$ & C & $\begin{array}{c}\text { Cuku } \\
\mathrm{p} \\
\text { baik }\end{array}$ & $\begin{array}{l}2 \\
0\end{array}$ & $50 \%$ & 15 & $\begin{array}{c}37,5 \\
\%\end{array}$ & $44 \%$ \\
\hline \multicolumn{3}{|c|}{ Jumlah } & $\begin{array}{l}4 \\
0\end{array}$ & $\begin{array}{c}100 \\
\%\end{array}$ & 40 & $100 \%$ & $\begin{array}{c}100 \\
\%\end{array}$ \\
\hline
\end{tabular}

Berdasarkan penelitian yang dilaksanakan pada bulan Agustus s.d. Oktober 2018 terhadap 40 orang mahasiswa Penjas dengan tujuan untuk meningkatkan kualitas pembelajaran mahasiswa semester VII kelas A TA 2018/2019 pada matakuliah Futsal dengan Metode Rondo diperoleh hasil seperti tabel di atas.

\section{Proses Analisa Data}

Instrumen tes yang digunakan adalah tes keterampilan dasar dalam permainan futsal.

Tabel 1. Tes Passing yang Akan Dinilai

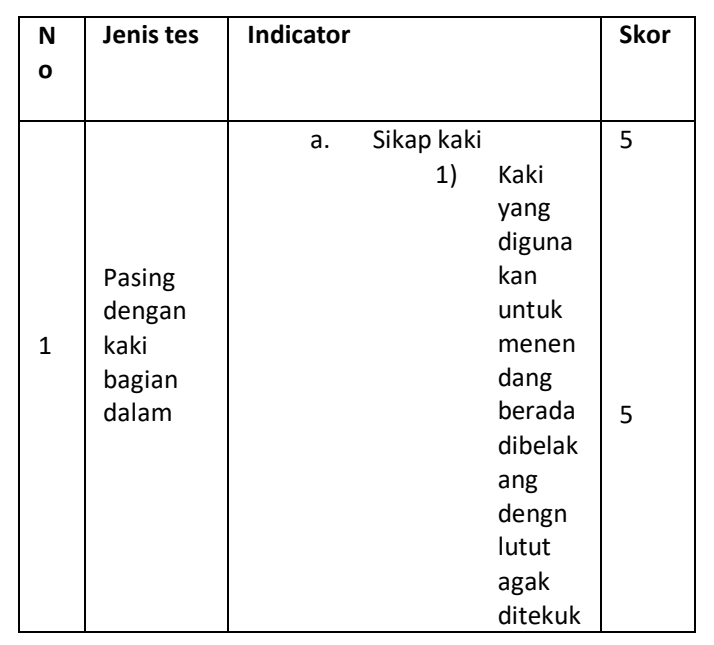

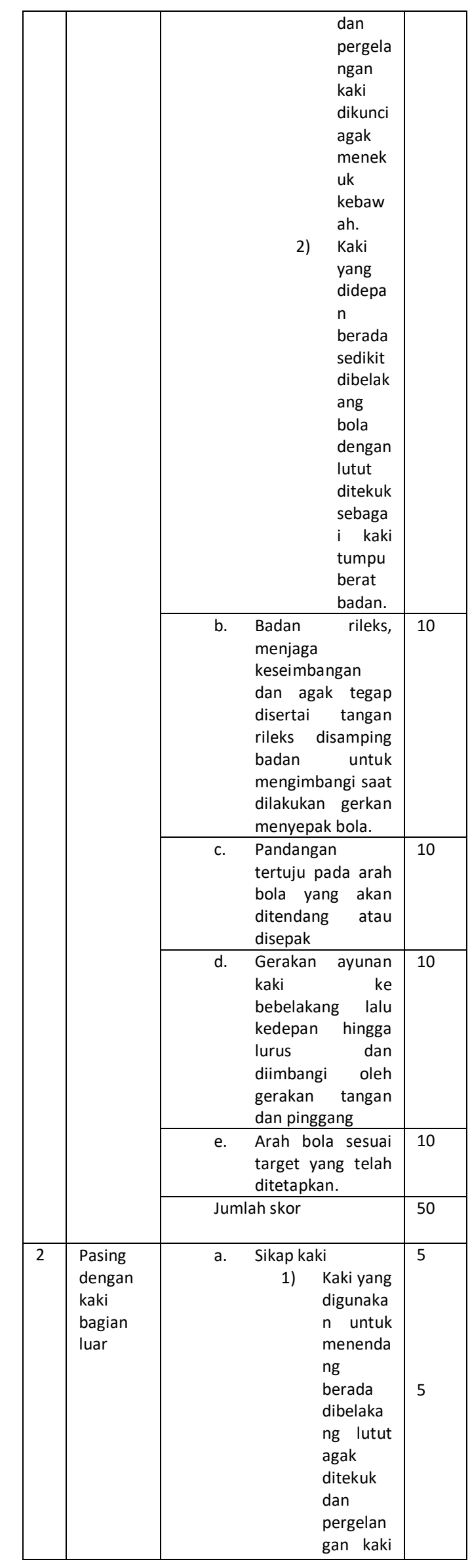




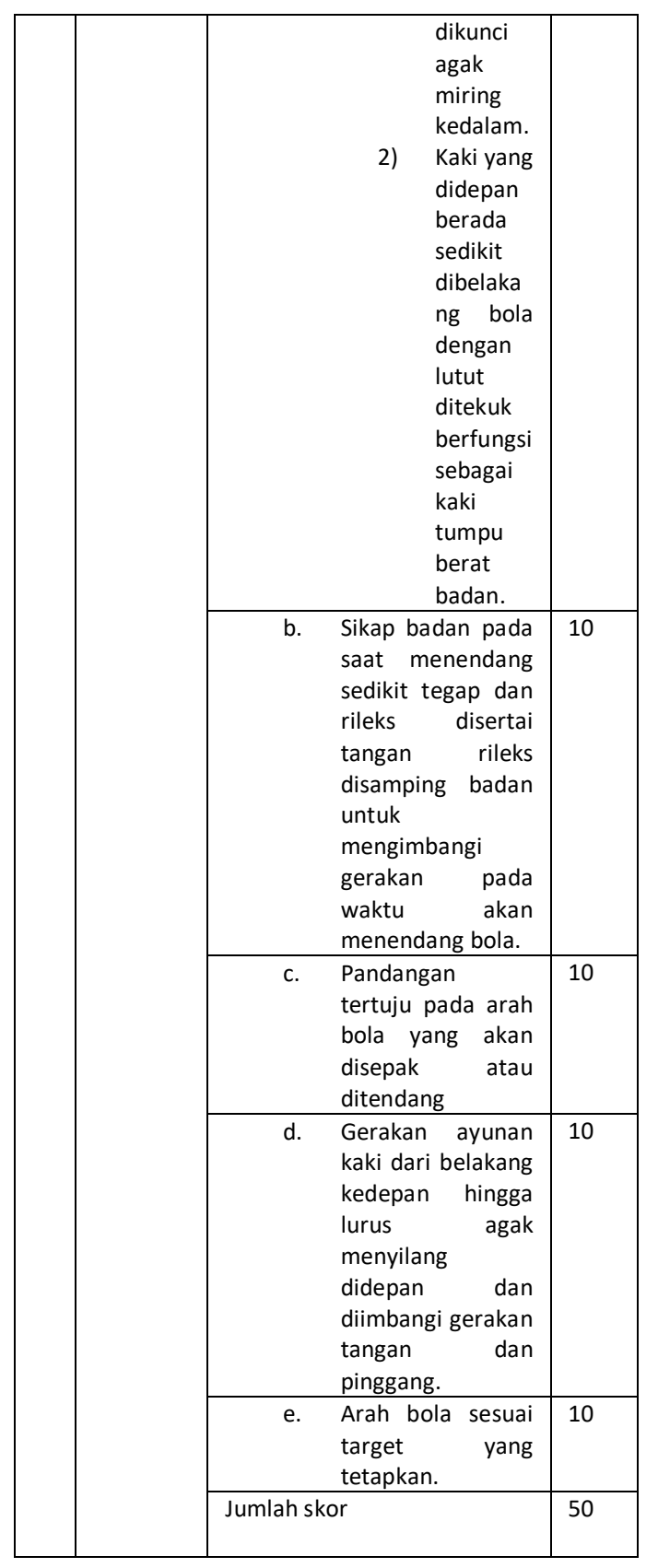

Beltasar Tarigan, $2001: 2$.

Pelaksanaan test teknik dasar dalam permainan futsal pada siswa yang berjumlah 40 orang. Sebelum melakukan tes siswa diberikan pengarahan mengenai test yang akan dilaksanakan dan diberikan motivasi agar siswa bersungguhsungguh dalam melakukan tes. Untuk mempermudah pengambilan data dan pelaksanaan kegiatan dapat berjalan secara optimal, peneliti meminta bantuan kepada teman-teman mahasiswa untuk membantu menjadi petugas pelaksanaan tes, pelaksanaan tes dalam permainan permainan futsal berupa (1) tes passing dengan kaki bagian dalam, (2) tes passing dengan kaki bagian luar.

Untuk menentukan kategori dari hasil tes tersebut digunakan tabel tes keterampilan teknik dasar passing pada permainan futsal seperti tabel di atas. Hasil (1) tes passing dengan kaki bagian dalam (2) tes passing dengan kaki bagian luar. Penggunaan tabel nilai dan norma yang dilakukan pada pelaksanaan tes itu harus disesuaikan dngan tabel penilaian.

Tabel 2. Hasil Siklus I dengan Menggunakan Metode Rondo

\begin{tabular}{|c|c|c|c|c|}
\hline No & Nama & $\begin{array}{l}\text { L/ } \\
P\end{array}$ & Nilai & $\begin{array}{l}\text { Ketera } \\
\text { ngan }\end{array}$ \\
\hline 1 & $\begin{array}{l}\text { Firman } \\
\text { Yohan } \\
\text { es }\end{array}$ & $\mathrm{L}$ & 80 & Tuntas \\
\hline 2 & $\begin{array}{l}\text { Bayu } \\
\text { Aji P }\end{array}$ & $\mathrm{L}$ & 60 & $\begin{array}{l}\text { Belum } \\
\text { tuntas }\end{array}$ \\
\hline 3 & $\begin{array}{l}\text { Juli } \\
\text { Hando } \\
\text { ko }\end{array}$ & $\mathrm{L}$ & 55 & $\begin{array}{l}\text { Belum } \\
\text { tuntas }\end{array}$ \\
\hline 4 & $\begin{array}{l}\text { David } \\
\text { Novan } \\
\text { da }\end{array}$ & $\mathrm{L}$ & 75 & Tuntas \\
\hline 5 & $\begin{array}{l}\text { Wahyu } \\
\text { Nopra } \\
\text { nto }\end{array}$ & $L$ & 80 & Tuntas \\
\hline 6 & $\begin{array}{l}\text { Putra } \\
\text { Hasiola } \\
\mathrm{n}\end{array}$ & $\mathrm{L}$ & 65 & $\begin{array}{l}\text { Belum } \\
\text { tuntas }\end{array}$ \\
\hline
\end{tabular}




\begin{tabular}{|c|c|c|c|c|}
\hline 7 & $\begin{array}{l}\text { Aditya } \\
\text { Juliant } \\
\text { o }\end{array}$ & $\mathrm{L}$ & 75 & Tuntas \\
\hline 8 & $\begin{array}{l}\text { Ranti } \\
\text { Suprap } \\
\text { to }\end{array}$ & $P$ & 55 & $\begin{array}{l}\text { Belum } \\
\text { tuntas }\end{array}$ \\
\hline 9 & $\begin{array}{l}\text { Tri } \\
\text { Rahma } \\
\text { dianti }\end{array}$ & $P$ & 80 & Tuntas \\
\hline 10 & $\begin{array}{l}\text { Zulha } \\
\text { m } \\
\text { Japrian } \\
\text { syah }\end{array}$ & $\mathrm{L}$ & 60 & $\begin{array}{l}\text { Belum } \\
\text { tuntas }\end{array}$ \\
\hline 11 & $\begin{array}{l}\text { Widi } \\
\text { kurnia } \\
\text { wan }\end{array}$ & $L$ & 80 & Tuntas \\
\hline 12 & $\begin{array}{l}\text { Wildan } \\
\text { sakti }\end{array}$ & $L$ & 75 & Tuntas \\
\hline 13 & $\begin{array}{l}\text { Angga } \\
\text { Febrin } \\
\text { aldo }\end{array}$ & $L$ & 60 & $\begin{array}{l}\text { Belum } \\
\text { tuntas }\end{array}$ \\
\hline 14 & $\begin{array}{l}\text { Dian } \\
\text { Septi }\end{array}$ & $P$ & 55 & $\begin{array}{l}\text { Belum } \\
\text { tuntas }\end{array}$ \\
\hline 15 & $\begin{array}{l}\text { Dika } \\
\text { Irwant } \\
\text { o }\end{array}$ & $L$ & 60 & $\begin{array}{l}\text { Belum } \\
\text { tuntas }\end{array}$ \\
\hline 16 & $\begin{array}{l}\text { M.Arid } \\
\mathrm{i}\end{array}$ & $\mathrm{L}$ & 60 & $\begin{array}{l}\text { Belum } \\
\text { tuntas }\end{array}$ \\
\hline 17 & $\begin{array}{l}\text { Bunga } \\
\text { Surya } \\
\text { Ningru } \\
\mathrm{m}\end{array}$ & $P$ & 60 & $\begin{array}{l}\text { Belum } \\
\text { tuntas }\end{array}$ \\
\hline 18 & $\begin{array}{l}\text { Bayu } \\
\text { Aditya }\end{array}$ & $\mathrm{L}$ & 50 & $\begin{array}{l}\text { Belum } \\
\text { tuntas }\end{array}$ \\
\hline 19 & $\begin{array}{l}\text { Gilang } \\
\text { Penges } \\
\text { tu }\end{array}$ & $L$ & 75 & Tuntas \\
\hline
\end{tabular}

\begin{tabular}{|c|c|c|c|c|}
\hline 20 & $\begin{array}{l}\text { Bagus } \\
\text { Purna } \\
\text { ma }\end{array}$ & $L$ & 60 & $\begin{array}{l}\text { Belum } \\
\text { tuntas }\end{array}$ \\
\hline 21 & $\begin{array}{l}\text { Wahyu } \\
\text { Saputr } \\
\text { a }\end{array}$ & $L$ & 80 & Tuntas \\
\hline 22 & $\begin{array}{l}\text { Nia } \\
\text { Oktavi } \\
\text { ani }\end{array}$ & $P$ & 60 & $\begin{array}{l}\text { Belum } \\
\text { tuntas }\end{array}$ \\
\hline 23 & $\begin{array}{l}\text { Bagus } \\
\text { Hidaya } \\
\text { t }\end{array}$ & $L$ & 80 & Tuntas \\
\hline 24 & $\begin{array}{l}\text { Yusuf } \\
\text { Apriadi }\end{array}$ & $L$ & 80 & Tuntas \\
\hline 25 & $\begin{array}{l}\text { M. } \\
\text { Ikhsan }\end{array}$ & $L$ & 75 & Tuntas \\
\hline 26 & $\begin{array}{l}\text { Buyun } \\
\text { g Khalil }\end{array}$ & $\mathrm{L}$ & 85 & Tuntas \\
\hline 27 & $\begin{array}{l}\text { Marsel } \\
\text { inus } \\
\text { Vicky }\end{array}$ & $L$ & 60 & $\begin{array}{l}\text { Belum } \\
\text { tuntas }\end{array}$ \\
\hline 28 & $\begin{array}{l}\text { Suwan } \\
\text { di } \\
\text { Syahpu } \\
\text { tra }\end{array}$ & $\mathrm{L}$ & 85 & Tuntas \\
\hline 29 & $\begin{array}{l}\text { Panji } \\
\text { Alpian }\end{array}$ & $\mathrm{L}$ & 60 & $\begin{array}{l}\text { Belum } \\
\text { tuntas }\end{array}$ \\
\hline 30 & $\begin{array}{l}\text { Dadan } \\
\text { g } \\
\text { Sulisty } \\
\text { o }\end{array}$ & $L$ & 80 & Tuntas \\
\hline 31 & $\begin{array}{l}\text { Gia } \\
\text { Ulfa }\end{array}$ & $P$ & 75 & Tuntas \\
\hline 32 & $\begin{array}{l}\text { Amirul } \\
\text { Sodiq }\end{array}$ & $\mathrm{L}$ & 85 & $\begin{array}{l}\text { Belum } \\
\text { tuntas }\end{array}$ \\
\hline 33 & $\begin{array}{l}\text { Manga } \\
\text { lap }\end{array}$ & $\mathrm{L}$ & 60 & Belum \\
\hline
\end{tabular}




\begin{tabular}{|c|c|c|c|c|}
\hline & \multicolumn{2}{|l|}{ Sangap } & & tuntas \\
\hline 34 & $\begin{array}{l}\text { Beni } \\
\text { Novsir }\end{array}$ & $\mathrm{L}$ & 65 & $\begin{array}{l}\text { Belum } \\
\text { tuntas }\end{array}$ \\
\hline 35 & $\begin{array}{l}\text { Rahma } \\
\mathrm{t} \\
\text { Hidaya } \\
\mathrm{t}\end{array}$ & $\mathrm{L}$ & 80 & Tuntas \\
\hline 36 & $\begin{array}{l}\text { Yoga } \\
\text { Sahput } \\
\text { ra }\end{array}$ & $L$ & 70 & Tuntas \\
\hline 37 & $\begin{array}{l}\text { Budi } \\
\text { Harton } \\
\text { o }\end{array}$ & $L$ & 60 & $\begin{array}{l}\text { Belum } \\
\text { tuntas }\end{array}$ \\
\hline 38 & $\begin{array}{l}\text { Fuad } \\
\text { Fadhill } \\
\text { ah }\end{array}$ & $L$ & 60 & $\begin{array}{l}\text { Belum } \\
\text { tuntas }\end{array}$ \\
\hline 39 & $\begin{array}{l}\text { Anggu } \\
\mathrm{n} \\
\text { Sastra }\end{array}$ & $P$ & 70 & Tuntas \\
\hline 40 & Berlian & $L$ & 65 & $\begin{array}{l}\text { Belum } \\
\text { tuntas }\end{array}$ \\
\hline Jun & 277 & & & \\
\hline $\begin{array}{l}\text { Rat } \\
69 .\end{array}$ & rata & & & \\
\hline
\end{tabular}

\section{Keterangan :}

1). Belum tuntas jika siswa mendapat nilai 0-69.

2). Tuntas jika siswa mendapat nilai 70-100.

Tabel 3. Hasil Siklus II dengan Menggunakan Metode Rondo

\begin{tabular}{|l|l|l|l|l|}
\hline N & Nama & L & Nilai & Ketera \\
o & & $/$ & & ngan \\
& & $\mathrm{P}$ & & \\
\hline
\end{tabular}

\begin{tabular}{|c|c|c|c|c|}
\hline 1 & $\begin{array}{l}\text { Firman } \\
\text { Yohanes }\end{array}$ & $\mathrm{L}$ & 80 & Tuntas \\
\hline 2 & $\begin{array}{l}\text { Bayu Aji } \\
\text { P }\end{array}$ & $\mathrm{L}$ & 80 & Tuntas \\
\hline 3 & $\begin{array}{l}\text { Juli } \\
\text { Handoko }\end{array}$ & $\mathrm{L}$ & 60 & $\begin{array}{l}\text { Belum } \\
\text { tuntas }\end{array}$ \\
\hline 4 & $\begin{array}{l}\text { David } \\
\text { Novanda }\end{array}$ & $L$ & 75 & Tuntas \\
\hline 5 & $\begin{array}{l}\text { Wahyu } \\
\text { Noprant } \\
\text { o }\end{array}$ & $\mathrm{L}$ & 80 & Tuntas \\
\hline 6 & $\begin{array}{l}\text { Putra } \\
\text { Hasiolan }\end{array}$ & $\mathrm{L}$ & 65 & $\begin{array}{l}\text { Belum } \\
\text { tuntas }\end{array}$ \\
\hline 7 & $\begin{array}{l}\text { Aditya } \\
\text { Julianto }\end{array}$ & $\mathrm{L}$ & 75 & Tuntas \\
\hline 8 & $\begin{array}{l}\text { Ranti } \\
\text { Suprapto }\end{array}$ & $P$ & 60 & $\begin{array}{l}\text { Belum } \\
\text { tuntas }\end{array}$ \\
\hline 9 & $\begin{array}{l}\text { Tri } \\
\text { Rahmadi } \\
\text { anti }\end{array}$ & $\mathrm{P}$ & 80 & Tuntas \\
\hline 10 & $\begin{array}{l}\text { Zulham } \\
\text { Japriansy } \\
\text { ah }\end{array}$ & $\mathrm{L}$ & 80 & Tuntas \\
\hline 11 & $\begin{array}{l}\text { Widi } \\
\text { kurniawa } \\
\text { n }\end{array}$ & $\mathrm{L}$ & 80 & Tuntas \\
\hline 12 & $\begin{array}{l}\text { Wildan } \\
\text { sakti }\end{array}$ & $\mathrm{L}$ & 75 & Tuntas \\
\hline 13 & $\begin{array}{l}\text { Angga } \\
\text { Febrinal } \\
\text { do }\end{array}$ & $L$ & 60 & $\begin{array}{l}\text { Belum } \\
\text { tuntas }\end{array}$ \\
\hline 14 & $\begin{array}{l}\text { Dian } \\
\text { Septi }\end{array}$ & $\mathrm{P}$ & 75 & Tuntas \\
\hline 15 & $\begin{array}{l}\text { Dika } \\
\text { Irwanto }\end{array}$ & L & 60 & $\begin{array}{l}\text { Belum } \\
\text { tuntas }\end{array}$ \\
\hline
\end{tabular}




\begin{tabular}{|c|c|c|c|c|}
\hline 16 & M.Aridi & $\mathrm{L}$ & 60 & $\begin{array}{l}\text { Belum } \\
\text { tuntas }\end{array}$ \\
\hline 17 & $\begin{array}{l}\text { Bunga } \\
\text { Surya } \\
\text { Ningrum }\end{array}$ & $\mathrm{P}$ & 60 & $\begin{array}{l}\text { Belum } \\
\text { tuntas }\end{array}$ \\
\hline 18 & $\begin{array}{l}\text { Bayu } \\
\text { Aditya }\end{array}$ & $\mathrm{L}$ & 60 & $\begin{array}{l}\text { Belum } \\
\text { tuntas }\end{array}$ \\
\hline 19 & $\begin{array}{l}\text { Gilang } \\
\text { Pengestu }\end{array}$ & $\mathrm{L}$ & 75 & Tuntas \\
\hline 20 & $\begin{array}{l}\text { Bagus } \\
\text { Purnama }\end{array}$ & $\mathrm{L}$ & 60 & $\begin{array}{l}\text { Belum } \\
\text { tuntas }\end{array}$ \\
\hline 21 & $\begin{array}{l}\text { Wahyu } \\
\text { Saputra }\end{array}$ & $L$ & 80 & Tuntas \\
\hline 22 & $\begin{array}{l}\text { Nia } \\
\text { Oktavian } \\
\text { i }\end{array}$ & $\mathrm{P}$ & 60 & $\begin{array}{l}\text { Belum } \\
\text { tuntas }\end{array}$ \\
\hline 23 & $\begin{array}{l}\text { Bagus } \\
\text { Hidayat }\end{array}$ & $\mathrm{L}$ & 80 & Tuntas \\
\hline 24 & $\begin{array}{l}\text { Yusuf } \\
\text { Apriadi }\end{array}$ & $\mathrm{L}$ & 80 & Tuntas \\
\hline 25 & $\begin{array}{l}\text { M. } \\
\text { Ikhsan }\end{array}$ & $\mathrm{L}$ & 75 & Tuntas \\
\hline 26 & $\begin{array}{l}\text { Buyung } \\
\text { Khalil }\end{array}$ & $\mathrm{L}$ & 85 & Tuntas \\
\hline 27 & $\begin{array}{l}\text { Marselin } \\
\text { us Vicky }\end{array}$ & $\mathrm{L}$ & 60 & $\begin{array}{l}\text { Belum } \\
\text { tuntas }\end{array}$ \\
\hline 28 & $\begin{array}{l}\text { Suwandi } \\
\text { Syahputr } \\
\text { a }\end{array}$ & $\mathrm{L}$ & 85 & Tuntas \\
\hline 29 & $\begin{array}{l}\text { Panji } \\
\text { Alpian }\end{array}$ & $\mathrm{L}$ & 80 & Tuntas \\
\hline 30 & $\begin{array}{l}\text { Dadang } \\
\text { Sulistyo }\end{array}$ & $\mathrm{L}$ & 80 & Tuntas \\
\hline 31 & Gia Ulfa & $\mathrm{P}$ & 75 & Tuntas \\
\hline
\end{tabular}

\begin{tabular}{|l|l|l|l|l|}
\hline 32 & $\begin{array}{l}\text { Amirul } \\
\text { Sodiq }\end{array}$ & L & 85 & Tuntas \\
\hline 33 & $\begin{array}{l}\text { Mangala } \\
\text { p Sangap }\end{array}$ & L & 60 & $\begin{array}{l}\text { Belum } \\
\text { tuntas }\end{array}$ \\
\hline 34 & $\begin{array}{l}\text { Beni } \\
\text { Novsir }\end{array}$ & L & 80 & Tuntas \\
\hline 35 & $\begin{array}{l}\text { Rahmat } \\
\text { Hidayat }\end{array}$ & L & 80 & Tuntas \\
\hline 36 & $\begin{array}{l}\text { Yoga } \\
\text { Sahputra }\end{array}$ & L & 70 & Tuntas \\
\hline 37 & $\begin{array}{l}\text { Budi } \\
\text { Hartono }\end{array}$ & L & 80 & Tuntas \\
\hline 38 & $\begin{array}{l}\text { Fuad } \\
\text { Fadhillah }\end{array}$ & L & 60 & $\begin{array}{l}\text { Belum } \\
\text { tuntas }\end{array}$ \\
\hline 39 & $\begin{array}{l}\text { Anggun } \\
\text { Sastra }\end{array}$ & P & 70 & Tuntas \\
\hline 40 & Berlian \\
Ban & L & 65 & $\begin{array}{l}\text { Belum } \\
\text { tuntas }\end{array}$ \\
\hline
\end{tabular}

\section{PEMBAHASAN}

Pembahasan dan Pengambilan Kesimpulan Hasil penelitian menunjukkan bahwa terdapat peningkatan kemampuan keterampilan dasar passing pada futsal melalui permainan metode rondo dilakukan tes teknik dasar passing permainan futsal. Secara keseluruhan hasil penelitian menunjukan adanya peningkatan seperti grafik berikut. 
Nilai Siswa

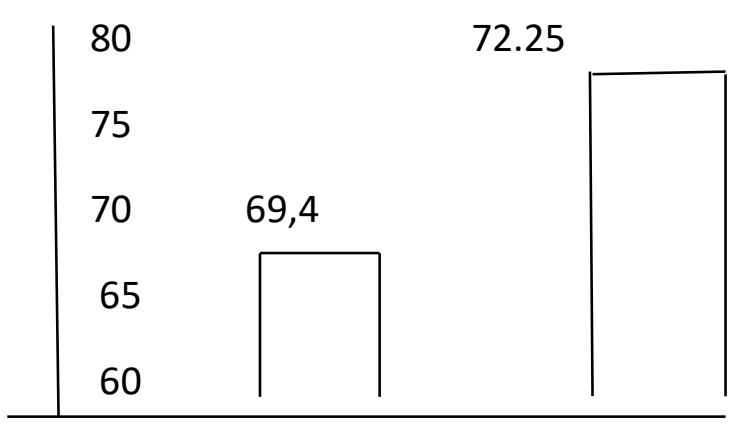

Siklus I Siklus II

\section{Grafik 1. Nilai Rata-Rata Per-Siklus}

Dari tabel dan grafik di atas tampak sekali adanya peningkatan keterampilan teknik dasar passing melalui latihan metode rondo, meskipun ada siswa yang belum tuntas pada siklus 2 . Setelah diberikan latihan dengan metode rondo dengan 1 orang yang menjadi penjaga bola pada siklus 1 kemampuan teknik dasar siswa meningkat, meskipun hanya 20 orang yang dikatakan tuntas dari 40 siswa dengan nilai rata-rata 69.4. Dari tes 2 orang yang menjadi penjaganya pada siklus 2, kemampuan teknik dasar passing pada futsal semakin meningkat dibuktikan dengan hasil penelitian 36 siswa dikatakan tuntas dari 40 siswa dengan nilai rata-rata 72.25 . Peningkatan yang diperoleh dari siklus I dan II adalah 6.53. Walaupun masih ada 14 siswa belum tuntas, pada siklus 2 sudah membuktikan bahwa dengan metode rondo bisa meningkatkan kemampuan passing pada permainan futsal. Oleh karena itu, peneliti tidak melanjutkan pada siklus 3 karena peneliti meyakini kemampuan siswa akan meningkat pada siklus 3 .

\section{KESIMPULAN}

Dari hasil penelitian yang telah dilakukan, dapat disimpulkan sebagai berikut; a) Ada peningkatan keterampilan teknik dasar passing dari sebelum menggunakan metode rondo dan sesudah menggunakan permainan metode rondo pada siklus I, yaitu terbukti ada peningkatan dari $50 \%$ dari 20 mahasiswa yang mendapat nilai tuntas dari jumlah 40 mahasiswa berdasarkan rincian persentase nilai (A) 12 orang, (B) 8 orang, (C) 20 orang dengan menggunakan metode rondo dengan 1 orang yang menjadi penjaga, b) Pada siklus II ada peningkatan keterampilan passing dalam permainan futsal metode rondo dengan 2 siswa yang menjadi penjaga. Terbukti dari hasil penelitian dengan hasil peningkatan $65 \%$ tuntas dari siklus I yang hanya $50 \%$ tuntas dari 40 siswa dengan rincian nilai (A) 16 orang, (B) 9 orang, (C) 15 orang. Tampak peningkatan dari siklus I yaitu $15 \%$ peningkatan dengan ketuntasan dari 20 mahasiswa menjadi 26 mahasiswa yang tuntas dalam pembelajaran Futsal.

\section{DAFTAR PUSTAKA}

Aqib, Z. 2006. Profesional Guru dalam Pembelajaran Olahraga. Surabaya: Cendikia

Harsono. 1998. Choaching dan Aspek-Aspek Psikologis dalam Choaching. Jakarta : Depdiknas

Kurniawan, Feri. 2011. Buku Pintar Olahraga. Jakarta : Laskar Aksara. 
Lhasana,J. 2011. Taktik dan Strategi

Futsal Modern. Jakarta : Be Champion

Mulyono, Asryardi, 2014. Buku Pintar Panduan Futsal, Banda Aceh : Laskar Aksara

Sukintaka. 1997. Bermain Futsal. Yogyakarta: $\quad$ FPOK-IKIP Yogyakarta.

Tarigan, B. 2001.Pendekatan Keterampilan Taktis Dalam Pembelajaran Sepak Bola. Jakarta: Direktorat Jendral olahraga.

Tenang, J. D. 2007. Mahir Bermain Futsal. Jakarta: Dar Mizan.

Pembelajaran Kooperatif : Teori, riset dan Praktek. Bandung : Nusa Media.

Supandi. (1992). Strategi Belajar MengajarPendidikan Jasmani. Jakarta: Depdikbud

Rusli Lutan. (1988). Belajar Keterampilan Motorik Pengantar Teori dan Metode. Jakarta: Depdikbud.

Rusli Lutan. (Perencanaan dan Startegi Pembelajaran Penjaskes. Jakarta: Dikutentis. 